\title{
Infrastructure and long-run economic growth: evidence from Chinese provinces
}

\author{
Bazoumana Ouattara ${ }^{1}$ • Yin-Fang Zhang ${ }^{1}$
}

Received: 14 June 2016 / Accepted: 21 February 2018 / Published online: 25 May 2018

(C) The Author(s) 2018

\begin{abstract}
This paper attempts to shed empirical light on one of the oldest debates in the literature on infrastructure-whether infrastructure capital contributes to aggregate output in the long run, and related to that, whether investing in infrastructure is an effective tool to promote regional development. Drawing from a panel data set of 29 Chinese provinces over the period 1985-2012, it constructs a synthetic infrastructure index and employs panel time series techniques. The findings suggest that infrastructure is, on average, a strong determinant of economic growth and that there are provincial differences in the marginal productivity of infrastructure due probably to differences in the relative shortage or overprovision of infrastructure stocks. Therefore, policy makers should use infrastructure investment as a means of boosting output or promoting regional development only to the extent that it does not lead to oversupply of infrastructure.
\end{abstract}

Keywords Infrastructure $\cdot$ Economic growth $\cdot$ Regional development $\cdot$ China

JEL Classification L9 $\cdot \mathrm{O} 1 \cdot \mathrm{O} 4$

$凶 \quad$ Yin-Fang Zhang

Yin-fang.zhang@manchester.ac.uk

Bazoumana Ouattara

osman.ouattara-2@manchester.ac.uk

1 Global Development Institute, School of Environment, Education and Development,

Universityof Manchester, Oxford Road, Manchester M13 9PL, UK 


\section{Introduction}

The effect of infrastructure on aggregate output and productivity has long been debated by researchers and practitioners. Many countries have relied on investment in infrastructure to boost output and promote economic development. Among them is China, whose zest for infrastructure construction started as early as the 1980s and continued in the new century with various development programmes aiming at stimulating regional growth and reducing regional development disparities. Overall, the country spent an average 8.5\% of its GDP on infrastructure over the period of 1992-2011, overtaking the USA and the European Union to become the world's largest investor in infrastructure.

However, China's large-scale investment in infrastructure has raised concerns among economists and policy makers. One of the issues is whether massive and continuous injection of capital into infrastructure projects can help the country maintain its growth in a sustainable manner. Another question of interest is whether improving infrastructure in less developed areas can boost regional economic growth. These concerns are not just specific to China, but also relate to the probably oldest debate in the literature on infrastructure. That is, whether infrastructure capital can contribute to aggregate output in the long run.

The literature on the role of infrastructure could perhaps be traced back to the works of Rosenstein-Rodan (1943) and Hirschman (1957), which have highlighted the importance of capital investment in promoting growth. However, it is not until the 1970s (see, e.g. Arrow and Kurz 1970) and in the 1980s and 1990s (see Romer 1986, 1990; Lucas 1988; Barro 1990) that public capital has been theoretically modelled in an aggregate production function. Empirical studies on the impact of infrastructure took off with the seminal work of Aschauer (1989), which concludes that the marginal productivity of public infrastructure spending is two to four times higher than that of private capital. Large output elasticities of infrastructure are also found in subsequent studies by Munnell (1990) and Ford and Poret (1991). However, these findings have been questioned on methodological grounds and the high rates of return to infrastructure investment reported are often dismissed as implausible. One of the major caveats of the earlier studies and, to a less extent, some later ones is the failure to take into account non-stationarity of the data, which may lead to the spurious regression problem - a possible reason for unrealistically high estimates of the productivity of infrastructure (Gramlich 1994). Some studies attempt to avoid this problem by transforming data into first differences, but at the expense of destroying the longterm relationships (Munnell 1992). Another issue of concern is the potential reverse causality between output and infrastructure investment. Failing to take into account the problem runs the risk of jumbling the estimates of the output elasticity of infrastructure with the income elasticity of the demand for infrastructure services, leading to biased estimation results. ${ }^{1}$

\footnotetext{
1 It should be noted that unobservable factors which affect both income and infrastructure investment may also lead to estimation biases, due to the potential correlation between the infrastructure variable and the error term. One way to deal with this problem is to introduce fixed effects into the specification.
} 
This paper joins the discourse by investigating the contribution of infrastructure to aggregate output based on empirical evidence from China. Over the last three decades, China experienced phenomenal economic growth, enlarging regional development disparities and waves of massive infrastructure investment made by both national and provincial governments as part of development policy packages. Thus, Chinese provinces provide an interesting empirical context to shed light on whether infrastructure capital has a long-run effect on aggregate output. To address the aforementioned methodological issues of earlier studies, we follow Calderón et al. (2015) and adopt a panel cointegration approach to deal with the non-stationarity of the variables included in our model and investigate the long-run effect of infrastructure. Although there has been a growing body of literature looking at the impact of infrastructure drawing from data on Chinese provinces (e.g. Demurger 2001; Ding et al. 2008; Fan and Chan-Kang 2008; Shiu and Lam 2008; Yu et al. 2012, 2013; Shi and Huang 2014), the analysis in this paper adopts an empirical strategy which distinguishes itself in some ways from existing China-specific studies.

First, our paper focuses on steady-state long-term relationships, a research issue which is difficult for most earlier studies to address due to short sample periods that do not allow some of infrastructure's effects (like indirect ones) to set in. More recent studies do employ longer periods (e.g. Shiu and Lam 2008; Yu et al. 2012, 2013), but the sample period used in this paper covers the years over which there were most marked changes in both aggregate output and infrastructure stocks. Secondly, in order to ascertain that estimates of the output elasticity of infrastructure are not confounded with the income elasticity of the demand for infrastructure, this paper tests the direction of causality based on the procedure developed by Dumitrescu and Hurlin (2012). Thirdly, existing China-specific studies usually focus on individual types of infrastructure. This paper considers the multidimensional aspect of infrastructure by constructing synthetic indicators, using principal component analysis (PCA) from four core infrastructure assets, namely electric power, telecommunications, paved roads and railways. Surely, it is important to examine the impact of individual infrastructure types, which may vary to some extent from one category to another. However, as noted by Agénor (2010), different infrastructure networks are complementary to each other. For instance, having electricity to produce commodities but no roads to carry them to the markets limits the productivity effects of a programme designed to expand electricity generation capacity and transmission networks. Therefore, it is the joint availability or operation that will generate more efficiency gains in a growing economy (Agénor 2010). The use of synthetic infrastructure indices in our paper is motivated to capture multidimensionality and the overall availability of infrastructure. Indeed, two composite infrastructure indictors are constructed-one derived from the conventional method of PCA and the other based on Robust PCA which takes into account outliers.

Finally, we do not assume a common linear production function, due to an observed factor specific to each province in our sample. To this end, we derive the pooled mean group estimates as well as the estimates for each of the sample provinces. This makes our approach different from existing studies which usually address heterogeneity in infrastructure's impact by running separate regressions for sub-samples of geographical areas. The analysis allows us to examine whether there is provincial difference in the infrastructure-growth nexus and explore possible explanations. It also casts light 
on a related research issue: whether increasing infrastructure investment in poor areas can help reduce regional development disparities.

It should be noted that our analysis using data on China has the potential to provide research insights and policy implications of wider relevance. China has transformed itself from one of the poorest countries in the world to a middle-income economy. Meanwhile, it has witnessed dramatic improvement in infrastructure facilities. The findings from such an empirical context regarding the long-run impact of infrastructure on aggregate output may be interesting to other developing countries. The part of the analysis which attempts to explore provincial differences in infrastructure's impact and possible underlying factors may be able to shed light on why infrastructure has high productivity in some locations but negligible effects in other places. Related policy implications are not just limited to China, but also relevant to other countries (even developed countries).

The rest of the paper is organised as follows. Next section provides a brief overview of economic growth and infrastructure development in China over the last 30 years. Sections 3 and 4 detail the econometric strategy and data issues, respectively. The results of the empirical analysis are presented in Sect. 5. The last section concludes.

\section{Economic growth and infrastructure in China}

Since the economic reform initiated in the late 1970s, China has experienced unprecedented economic growth, with GDP growth averaging about 10 per cent over the last three decades. The growth performance of China has, however, been uneven across provinces. The development strategy implemented in the pre-1979 era and the early years of economic reform put emphasis on heavy industries, which concentrated in the north-eastern provinces and part of the central region. Since the mid-1980s, provinces along the eastern coastline were encouraged to grow, where special economic zones were established and more and more firms started to export. The growth momentum of the region was accelerated after 1992 when more favourable policies were granted, making it the most economically advanced area of the country. In order to reduce the resultant regional development disparity and promote economic growth in interior provinces, the 'Open-up the West' Strategy was initiated from 2000, followed by the 'North-east Revival' and 'Rise of Central China' schemes.

Large amounts of resources have been mobilised in China to develop and improve infrastructure facilities. Investment made in the 1980s was to alleviate energy-related bottlenecks, and, therefore, priority was given to the development of the gas and oil, coal, and electric power sectors (Naughton 2007). The transport and telecommunication sectors received much less recourses for the ensuing years, with their share in state fixed-asset investment at around $10 \%$ in comparison with that of the energy sector at 20\% (Demurger 2001). Things started to change from 1992 when infrastructure was reasserted as a major development priority and implemented as an integral part of preferential policies applied to coastal provinces. This led to fast expansion of transport and telecoms facilities in the region. It was followed by an even faster growth in infrastructure investment around the year 1998, when infrastructure spending was used as an instrument of fiscal policy to stimulate economic growth. In the 
new millennium, with the unfolding of the programs aimed to promote economic development in the western, central and north-eastern parts of the country, both the central and local governments invested heavily in infrastructure projects, leading to significant improvement in the overall infrastructure endowments in these areas (Yu et al. 2012). In particular, provinces with abundant energy resources (e.g. Xinjiang and Inner Mongolia) received massive funding to build themselves as energy centres of the country. All the aforementioned infrastructure investments were topped up by a recent wave of infrastructure spending following the global financial crisis, making China the world's largest investor in infrastructure.

\section{Econometric methodology}

\subsection{Model specification}

Following the existing literature we adopt an augmented production function in which infrastructure appears alongside physical capital, labour and human capital as factors of production. Keeping with most of earlier studies, the assumption of constant returns to scale is imposed, which leads to the following empirical specification after taking logarithms of the variables and subtracting the labour variable from both sides of the equation:

$$
y_{i t}=\beta_{1} k_{i t}+\beta_{2} h c_{i t}+\beta_{3} z_{i t}+\gamma_{i}+\eta_{t}+\varepsilon_{i t} .
$$

$y_{i t}$ denotes the logarithm of output per worker in province $i$ at time $t ; k_{i t}$ denotes the logarithm of physical capital per worker; $z_{i t}$ is infrastructure capital per worker ${ }^{2}$; and $h c_{i t}$ stands for human capital. $\eta_{t}$ allows for time-specific effects, whilst $\gamma_{i}$ capture province-specific effects. The residual $\varepsilon_{i t}$ reflects the influence of shocks that affect the (log) level of output per worker which is assumed uncorrelated across provinces and over time.

Estimation results based on Eq. (1) may be spurious if individual variables in the specification are non-stationary. This is a methodological issue which many earlier studies and in particular those using data on Chinese provinces have failed to deal with. The first step in our empirical strategy is, therefore, to ascertain the time series properties of the variables.

\footnotetext{
2 Equation (1) corresponds exactly to the production function framework adopted by some influential studies like Canning (1999), Canning and Bennathan (2002), Canning and Pedroni (2007), Candelon et al. (2013) and Calderón et al. (2015). Infrastructure enters the equation twice: as part of physical capital $k$ and on its own. The genuine contribution of infrastructure to output can be approximated as $\psi \approx \beta_{3}+\varpi \beta_{1}$ where $\varpi$ is the share of infrastructure in the overall physical capital stock. Evaluation of this parameter requires data on prices or costs of infrastructure, which are unavailable and could be problematic in the context of China where prices of constructing infrastructure networks were or still are regulated by the government. Nonetheless, as suggested by Canning and Bennathan (2002) and Calderón and Servén (2004), $\varpi$ is typically a small number and therefore discrepancy between the genuine elasticity of output with respect to infrastructure and the coefficient estimate $\beta_{3}$ is little. As in the cited papers, a more precise interpretation of the result is that the productivity of infrastructure exceeds (if $\beta_{3}>0$ ) or falls short of (if $\beta_{3}<0$ ) that of non-infrastructure capital.
} 


\subsection{Unit root tests}

To test for the order of integration of the variables, we use panel data unit root tests. Indeed, we consider three tests, namely the Levin et al. (2002)-LLC, the Im et al. (2003)-IPS and the Pesaran (2007) panel unit root tests. The first two tests assume cross-sectional independence; however, if provinces are spatially dependent as they usually lie in the same geographical area, the assumption of the independence of error processes will be violated. Thus, the LLC and IPS tests in this context might lead to spurious results. The Pesaran (2007) test allows us to deal with this issue.

The basic framework followed by these tests can be viewed as an extension of the standard (augmented) Dickey-Fuller test and takes the following form:

$$
\Delta w_{i t}=g_{i t}^{\prime} \theta+\eta_{i} w_{i t-1}+\sum_{j=1}^{k} \rho_{i j} \Delta w_{i t-1}+\vartheta_{i t},
$$

where $w_{i t}$ denotes each variable under consideration, $k$ is the lag length, the vector $g_{i t}^{\prime}$ includes panel-specific fixed effects or panel-specific fixed time effects and is the corresponding vector of coefficients.

The LLC test assumes the coefficient of the auto-regressive term to be homogeneous across all $i$ (i.e. $\eta_{i}=\eta$ ) and examines the null hypothesis of $\mathrm{H}_{0}: \eta=0$ against the alternative $H_{1}: \eta<0$. In the IPS test, however, the coefficient of the auto-regressive term is allowed to vary across the different units. This test applies a standardised $t$-bar statistic which is based on estimating separate unit root tests and averaging their ADF $t$-statistics. That is, $\bar{t}=\sqrt{N}\left(t_{i T}-N^{-1} \sum_{i=1}^{N} E\left(t_{i T}\right)\right) / \sqrt{N^{-1} \sum_{i=1}^{N} \operatorname{var}\left(t_{i T}\right)}$, where $t_{i T}$ is the individual ADF $t$-statistics for the $\mathrm{N}$ cross-sectional units, and $E\left(t_{i T}\right)$ and $\operatorname{Var}\left(t_{i T}\right)$ are, respectively, the mean and variance of $t_{i T}$.

The Pesaran (2007) test addresses cross-sectional dependence by including the cross-sectional mean of the lagged values of $w_{i t}$ and its differences. The corresponding test is then defined as the simple average of the individual cross-sectional ADF regressions: CADF $=\frac{1}{N} \sum_{i=1}^{N} t_{i}$, where $t_{i}$ is the $t$ statistic of the OLS estimate of the auto-regressive term in the modified version of Eq. (2).

\subsection{Cointegration tests}

If the variables in our model are found non-stationary, one can proceed to test whether they are bound together in the long run, i.e. whether they are cointegrated. If so, Eq. (1) represents a long-run relationship between permanent movements in the (log) level of output per worker, infrastructure per worker, physical capital per worker and human capital. Several cointegration tests have been proposed in the literature, including Kao (1999)'s residual panel cointegration test and Pedroni (2000)'s residual panel cointegration test. However, as noted by Calderón et al. (2015), these tests only ascertain the presence of cointegration among the variables; but do not provide any information on the cointegration rank. These tests, therefore, implicitly assume the existence of one cointegrating relationship. In a model with four variables (as 
in our context), there is a possibility that more than one cointegration relationship exists. In order to ascertain whether there exists cointegration as well as the number of cointegration relations, this paper adopts the Johansen-Fisher panel cointegration test proposed by Larsson et al. (2001).

To illustrate how the test is conducted, let us consider a panel data set that consists of a panel of $N$ cross-sectional units (provinces in our case) $(i=1, \ldots N)$ observed over $T$ time period $(t=1, \ldots T)$. The data generating process for each group in our sample can be represented by the following heterogenous vector error correction model:

$$
\Delta y_{i t}=\Pi_{i} y_{i, t-1}+\sum_{k=1}^{k_{i}-1} \Gamma_{i k} \Delta y_{i, t-k}+u_{i t} .
$$

$k$ is the number of lags; $u_{i t}$ is an i.i.d. error term; $\Pi=\alpha \beta^{\prime}$ with $\alpha$ being a $p \times$ $r$ matrix of short-run adjustment coefficients; and $\beta^{\prime}$ a $p \times r$ matrix of long-run cointegrating relations. The Johansen-Fisher panel cointegration procedure consists of testing the hypothesis that all of the $N$ groups in the panel have at most $r$ cointegrating relationships among the $p$ variables. For this end, Larsson et al. (2001) consider the following rank hypotheses, for all $i=1, \ldots N$

$$
\begin{gathered}
H_{0}: \operatorname{rank}\left(\Pi_{i}\right)=r_{i} \leq r \\
H_{1}: \operatorname{rank}\left(\Pi_{i}\right)=p .
\end{gathered}
$$

Similar to the trace statistics from Johansen (1995), the trace statistic for each group $i$ can be expressed as:

$$
L R_{i T}(H(\gamma) \mid H(p))=-2 \ln Q_{i T} H(\gamma) \mid H(p),
$$

where $H(r): \operatorname{rank}(\Pi) \leq r$ and $H(p): \operatorname{rank}(\Pi=p)$.

Defining the LR-bar statistic as the average of the $N$ individual trace statistics: $L R_{i T}(H(\gamma) \mid H(p))$, Larsson et al. (2001) propose the use of a standardised LR-bar statistic as a basis for the panel cointegration rank test, which is:

$$
\gamma_{\overline{L R}}(H(\gamma) \mid H(p))=\frac{\sqrt{N}\left(\overline{L R}(H(\gamma) \mid H(p))-E\left(Z_{k}\right)\right)}{\sqrt{\operatorname{var}\left(Z_{k}\right)}} .
$$

$E\left(Z_{k}\right)$ and $\operatorname{var}\left(Z_{k}\right)$ are, respectively, the mean and variance of the variable $Z$ which follows the same asymptotic distribution as the individual trace statistics.

To test for the existence of cointegration, one can let $r$ take the value 0 and see whether the null hypothesis $H_{0}: \operatorname{rank}(\Pi)=0$ can be rejected. In order to test whether there is only one single cointegration relation, one can impose the value of 1 on $r$ and see whether the hypothesis $H_{(r)}: \operatorname{rank}(\Pi) \leq 1$ is true. 


\subsection{Estimation of panel data model}

As our cointegration results show later, there exists a single cointegrating vector among the variables in Eq. (1). We interpret this single cointegration relation as the long-run production function and therefore adopt a single-equation approach to estimate the coefficients of the variables in concern. ${ }^{3}$ Several estimators for cointegrated panel data have been proposed in the literature. In choosing the appropriate estimator for purpose, we adopt the following strategy. First, we take the nature of our data set into consideration. Indeed, our data set consists of 29 Chinese provinces over the period 1985-2012; thus, $N=28$ and $T=28$ are moderate in size. Second, crosssectional dependence has become, increasingly, an important issue in panel data estimations. Thus, choosing an estimator that overcomes this problem is crucial in deriving consistent estimates. For this reason, we use two estimation techniques in the main analysis, namely Pesaran (2006)'s common correlated effects mean group (CCEMG) estimator and the augmented mean group (AMG) estimator introduced by Eberhartd (2012). These estimators allow for unobserved correlation across panel members (cross-sectional dependence). Moreover, it has been shown that the CCEMG estimator provides consistent estimates of the slope coefficients and standard errors under the more general case of multifactor error structure and spatial error correlation, and performs well in small samples and can handle the presence of autocorrelation in the residuals and unit roots in the common factors (Pesaran and Tosetti 2011). We also conduct a robustness check by using estimators proposed by Bai et al. (2009).

To implement the CCEMG, the error term in Eq. (1) can be rewritten as having a multifactor structure, in the form of $\varepsilon_{i t}=\omega_{i t}^{\prime} f_{t}+v_{t} . f_{t}$ is a vector of $k \times 1$ unobserved common factors, which affect each of the provinces with different intensities, and $v_{t}$ is the province-specific error term which is assumed to be weakly dependent across the cross-sectional units. Rewriting Eq. (1) as $y_{i t}=\delta_{i}^{\prime} x_{i t}+\gamma_{i}+\eta_{t}+\omega_{i t}^{\prime} f_{t}+v_{t}$, where $x_{i t}$ is the set of our regressors, one can obtain the estimated coefficient CCEMG as, $\widehat{\delta}_{\mathrm{CCEMG}}=N^{-1} \sum_{i} \widehat{\delta}_{i}$.

The AMG estimator improves on the standard mean group by including a 'common dynamic process' extracted from a pooled OLS regression of first differences, which provides a panel-equivalent average movement of the unobserved common factors. Common factors are those factors that are time specific and common across provinces. The AMG is a two-stage procedure, which can be expressed as follows:

$$
\begin{aligned}
& \text { stage(1): } \Delta y_{i t}=\delta_{i}^{\prime} \Delta x_{i t}+\sum_{t=2}^{T} c_{t} \Delta D_{t}+e_{t} \\
& \widehat{c}_{t} \equiv \widehat{\mu}_{t} \\
& \operatorname{stage}(2): y_{i t}=\delta_{i}^{\prime} x_{i t}+r+c_{i} t+d_{i} \widehat{\mu}_{t}+e_{t}
\end{aligned}
$$

\footnotetext{
3 Johansen (1992) shows that the single-equation estimators are equivalent to those based on the estimation of a system of all possible equations, although they may be inefficient under certain circumstances.
} 


$$
\widehat{\delta}_{\mathrm{AMG}}=N^{-1} \sum_{i} \widehat{\delta}_{i}
$$

where we have $(T-1)$ year dummies $D$ in first difference with corresponding parameter vector $c_{t}$ from which the year dummy coefficients that are relabelled as $\widehat{\mu}_{t}$ are collected. In the second stage, $\widehat{\mu}_{t}$ is included as an additional regressor in each of the $N$ standard province regressions which also include linear trend terms $t$ to capture omitted idiosyncratic processes that evolve in a linear fashion over time.

\subsection{Panel causality test}

The estimates of the output elasticity of infrastructure and associated inference obtained from the single-equation estimation based on Eq. (1) are only valid when infrastructure is weakly exogenous. If not, the estimates obtained could mix up the output elasticity of infrastructure with the income elasticity of the demand for infrastructure. To infer the causal relationship between the variables, we adopt the methodology developed by Dumitrescu and Hurlin (2012). This approach accounts for heterogeneity in the data series and assumes that all coefficients are different across the units in our sample. Dumitrescu and Hurlin (2012) extend the Granger (1969) contribution to panel data. To illustrate, let us assume $x_{i t}$ and $y_{i t}$ are the two stationary series (which could be the differences of non-stationary variables). To test whether $x$ Granger causes $y$, the following underlying model can be used:

$$
y_{i t}=a_{1}+\sum_{k=1}^{K} \theta_{i k} y_{i t-k}+\sum_{k=1}^{K} \delta_{i k} x_{i t-k}+\varpi_{i t}
$$

with $i=1, \ldots, N$ and $t=1, \ldots, T$. The procedure to determine the existence of causality consists of testing for significant effects of past values of $x$ on the present value of $y$. The null hypothesis, which corresponds to the absence of causality for all individuals in the panel, can thus be defined as:

$$
H_{0}: \delta_{i 1}=\delta_{i 2}=\cdots=\delta_{i K}=0, \quad \forall i=1, \ldots, N
$$

The alternative hypothesis can be written as:

$$
\begin{gathered}
H_{1}: \delta_{i 1}=\delta_{i 2}=\cdots=\delta_{i K}=0, \quad \forall i=1, \ldots, N_{1}, \\
\delta_{i 1} \neq 0, \text { or } \delta_{i 2} \neq 0 \text { or } \ldots \text { or } \delta_{i K} \neq 0, \quad \forall i=N_{1}+1, N_{1}+2, \ldots, N
\end{gathered}
$$

where $N_{1} \in[0, N-1]$ is unknown. For causality to exist for all individuals, the following must hold $N_{1}<N$; otherwise, the null hypothesis applies. If $N_{1}=0$, this would imply that there is causality for all individuals in the panel.

With the above in mind, Dumitrescu and Hurlin (2012) propose a Wald test derived from the average of individual Wald statistics associated with the test of the non- 
causality hypothesis for units $i=1, \ldots, N$. They define the average Wald associated with the null homogeneous non-causality hypothesis (HNC) as:

$$
W_{N T}^{H N C}=\frac{1}{N} \sum_{i=1}^{N} W_{i T},
$$

where $W_{i T}$ represents the Wald statistic for the $i$ th cross-sectional unit corresponding to the individual test $H_{0}: \delta_{i}=0$. Using Monte Carlo experiments, Dumitrescu and Hurlin (2012) show that the proposed standardised panel statistics have very good small sample properties and are robust in the presence of cross-sectional dependence.

\section{Data}

The data used in this paper consist of a balanced panel of 29 Chinese provinces over the period 1985-2012. Table 9 in Appendix provides the list of sample provinces. Output is measured by real GDP per worker in the 1987 prices. The variable physical capital is constructed using the perpetual inventory method. The values of provincial physical capital stocks for the year 1984 - the year before the beginning of the sample period-are taken from Zhang and $\mathrm{Wu}$ (2004). They are then used to calculate capital stocks for the sample period from 1985 to 2012, based on $K_{i t}=K_{i t-1}\left(1-\delta_{i t}\right)+I_{i t}$, where $\delta_{i t}$ denotes the depreciation rate and $I_{i t}$ the gross fixed capital formation. In line with Zhang and $\mathrm{Wu}$ (2004), 9.6\% is used as the depreciate rate in the calculation. ${ }^{4}$ Calculated capital stocks are converted to the 1987 prices by using the deflators obtained from China Statistical Yearbook and then transformed into the per worker terms by using the data on provincial employment from China Labour Statistical Yearbook. Human capital is proxied as the $\%$ of provincial population with at least 9 years of compulsory school education, with data from China Population Statistical Yearbook.

To capture the multidimensional nature of infrastructure capital, we consider four categories of infrastructure assets, namely electric power, telecoms, paved roads and railways. Electricity is measured by total amount of electricity generated, with data obtained from China Energy Statistical Yearbook. Telecoms infrastructure is measured by the number of landlines and cellular phones, and the two transport indicators are total length of paved roads and that of railway routes. The data are collected from China Statistical Yearbook. The indicators are converted into the per 1000 worker terms by using the data on provincial total employment from China Labour Statistical Yearbook. Summary statistics of the variables are provided in Table 1.

The strategy used in this paper is to construct a synthetic indicator of the four infrastructure stocks as a measure of the overall availability of infrastructure. By doing so, we can also deal with some empirical difficulties arising from introducing a variety of infrastructure indicators as inputs in the production function. Given that

\footnotetext{
4 Two alternative depreciation rates are also experimented. One is $6 \%$, as used in some empirical studies with cross-country data (e.g. Calderón et al. 2015); the other is a much higher rate $16 \%$, following studies such as Bai et al. (2006) and Shi and Huang (2014). However, the regression results based on thus calculated physical capital stocks are similar to the ones reported in Sect. 5.
} 
Table 1 Descriptive statistics

\begin{tabular}{lllll}
\hline Variables & Mean & S.D. & Min. & Max. \\
\hline $\begin{array}{l}\text { Real GDP per worker (10,000 Yuan) } \\
\begin{array}{l}\text { Physical capital stock per worker } \\
\quad(10,000 \text { Yuan) }\end{array}\end{array} 0^{\text {Human capital }}$ & 2.1265 & 2.6357 & 0.2212 & 20.3367 \\
$\begin{array}{l}\text { Electricity generation per 1000 } \\
\text { workers (10 million kwh) }\end{array}$ & 0.4850 & 0.1616 & 0.1093 & 0.8845 \\
$\begin{array}{l}\text { Landline and mobile phones per } \\
\quad \text { 1000 workers (no. of lines) }\end{array}$ & 0.3263 & 0.3304 & 0.0249 & 2.7650 \\
$\begin{array}{l}\text { Length of paved road per 1000 } \\
\quad \text { workers (km) }\end{array}$ & 620.5026 & 763.1551 & 3.33758 & 3658.7 \\
$\begin{array}{l}\text { Length of railway per 1000 worker } \\
(\mathrm{km})\end{array}$ & 0.15873 & 2.2422 & 0.2670 & 21.2276 \\
\hline
\end{tabular}

our estimations are based on panel cointegration analysis, it would be computationally difficult to accommodate all the four variables in a single regression (because of over-parametrisation). Another problem relates to multicollinearity if individual infrastructure indicators are highly correlated, as it is the case in our context. Bearing this in mind, we construct a composite index for infrastructure derived from principal component analysis (PCA), in which the underlying variables are standardised in order to abstract from their units of measurement. The analysis shows that the first principal component has an eigenvalue of 2.92, whilst other components have eigenvalues lower than 1 . The Kaiser rule suggests that we retain components with eigenvalue higher than 1. Moreover, the first component explains around $73 \%$ of the variance of the four variables. Finally, the overall Kaiser-Meyer-Olkin (KMO) measure of sampling adequacy is $72.5 \%$ with the individual KMO ranging from 67 to $81 \%$. Therefore, we use the first principle component to construct the composite infrastructure index, as follows:

$$
\begin{gathered}
0.54 \times \ln (\text { paved })_{i t}+0.55 \times \ln (\text { electricity })_{i t}+0.35 \\
\times \ln (\text { rail })_{i t}+0.53 \times \ln (\text { telecommunication })_{i t},
\end{gathered}
$$

where paved is the length of paved roads (in kilometres per 1000 workers); electricity is power generation (in 10 million kwh per 1000 workers); rail represents the length of rail lines (in kilometres per 1000 workers); and telecommunication is the number of main lines and mobile phones (per 1000 workers). The synthetic index is highly correlated with the individual infrastructure indicators used in its construction. More precisely, the correlation coefficients are $87 \%$ for paved roads, $96 \%$ for electricity generation, $74 \%$ for railways and $97 \%$ for telecommunications.

The standard approach of PCA as adopted above may become less valid because the covariance matrix used in the calculation may be sensitive to outliers (if any). To 
Table 2 Panel unit root results

\begin{tabular}{lrrr}
\hline & \multicolumn{1}{l}{ IPS } & LLC & Pesaran (2007) \\
\hline GDP & -0.493 & 3.650 & 2.306 \\
Physical capital & 1.949 & 3.067 & 1.787 \\
Human capital & 1.170 & 4.089 & -0.051 \\
Infrastructure-robust & -1.200 & 1.754 & 2.851 \\
Infrastructure 2 & -1.039 & 1.782 & 3.061 \\
\hline
\end{tabular}

(1) $5 \%$ critical value for the null hypothesis of unit root is -1.96 for the LLC and IPS test statistic and -2.56 for the Pesaran (2007) statistic. (2) Two lags were used in the estimations

overcome this potential problem, we construct another composite infrastructure index based on a robust principal component analysis, as follows:

$$
\begin{gathered}
0.49 \times \ln (\text { paved })_{i t}+0.52 \times \ln (\text { electricity })_{i t}+0.48 \\
\times \ln (\text { rail })_{i t}+0.51 \times \ln (\text { telecommunication })_{i t}
\end{gathered}
$$

We use this infrastructure index in the main regression analysis. Nevertheless, we also report the results using the composite indicator in which outliers are not dealt with, as the robustness check.

\section{Empirical results}

The analysis starts with checking the stationarity of the variables and testing for cointegration. It then moves on to the estimation of the long-run elasticities of output with regard to infrastructure and other inputs in the production function as specified in Eq. (1).

\subsection{Panel unit root tests and cointegration results}

Table 2 reports the results of the panel unit root tests. Both the IPS and LLC tests suggest that the null hypothesis of unit root cannot be rejected at the $5 \%$ significance level. The two tests are less valid if there is cross-sectional dependence, which is the case in our context (see Table 10 in Appendix). The results from the Pesaran (2007) test are therefore more insightful, which also point to non-stationarity of the variables. However, applying the tests to the first difference of the variables produces results which lead to the rejection of the null of non-stationarity. ${ }^{5}$ We therefore conclude that all the variables are $\mathrm{I}(1)$.

The next step is to test for cointegration. The results are summarised in Table 3, with the upper panel reporting those from the Johansen-Fisher test and the lower part the panel LR-bar test. Both the trace and eigen statistics from the Johansen-Fisher

\footnotetext{
5 Results are not reported here, but available upon request.
} 
Table 3 Panel cointegration test results

Johansen-Fisher panel cointegration test

\begin{tabular}{lllll}
\hline No. of cointegrations & Trace test & Prob. & Eigen test & Prob. \\
None & 195.9 & 0.000 & 142.2 & 0.000 \\
At most 1 & 96.01 & 0.13 & 65.19 & 0.2411 \\
\hline
\end{tabular}

Panel LR-bar test

\begin{tabular}{ll}
$H_{0}:$ rank $\leq r$ & Test statistics \\
0 & 16.25 \\
1 & 1.132 \\
\hline
\end{tabular}

The null hypothesis of maximum cointegration rank is sequentially tested against the alternative of maximum rank equal to $\mathrm{p}$ (i.e. the No. of variables considered). The $5 \%$ critical value is 1.96

test indicate the rejection of the null of no cointegration, and we therefore conclude that the variables are cointegrated. In order to find out the number of cointegration vectors, we rely on the panel LR-bar test. It is evident from the results that the null that the maximum rank is zero (i.e. no cointegration) is rejected. However, the test does not reject the maximum rank of 1 . Based on these results, it can be concluded that the null hypothesis of a common cointegrating rank for all provinces in the panel cannot be rejected. This implies that for each group in our sample, there exists one cointegrating relationship, which can be interpreted as the infrastructure-augmented production function as expressed in Eq. (1).

\subsection{Estimation results from long-run cointegration relationship}

As discussed earlier, the Pesaran (2006)'s common correlated effects mean group (CCEMG) estimator and the augmented mean group (AMG) estimator introduced by Eberhartd (2012) are adopted to estimate Eq. (1). One of the reasons to employ them relates to the concern of cross-sectional dependence. A test of cross-sectional dependence against the residuals obtained from the standard mean group estimator yields a test statistic of 44.93 (with a $p$ value of 0.00 ). This confirms the existence of the issue and justifies the use of CCEMG and AMG.

Table 4 reports the results using the synthetic infrastructure index based on robust PCA. The first thing to notice is that the two econometric methods produce very similar results: the parameter estimates are very similar in magnitude except for the variable of human capital which is nevertheless statistically insignificant. The estimated coefficient of physical capital is 0.254 from CCEMG and 0.225 from AMG, suggesting a long-run positive output elasticity of this variable. The magnitude of the coefficient is a bit lower than that found in the most influential cross-country studies using data sets which include observations on China (e.g. Canning 1999; Canning and Bennathan 2002; Calderón and Servén 2004; Candelon et al. 2013; Calderón et al. 2015). Although caution should be taken when comparing cross-province results like ours with those from cross-country studies, the relatively lower coefficients of physical 
Table 4 Estimation of long-run elasticities of output (period = 1985-2012; no. of provinces $=29$ )

\begin{tabular}{lll}
\hline & $(1)$ & $(2)$ \\
& CCEMG & AMG \\
\hline Physical capital & $0.254 * * *(0.0733)$ & $0.225^{* * *}(0.025)$ \\
Human capital & $0.294(0.180)$ & $0.084(0.096)$ \\
Infrastructure robust & $0.126^{* * *}(0.029)$ & $0.148^{* * *}(0.023)$ \\
Constant & $0.0821(0.257)$ & $-0.612 * * *(0.161)$ \\
Observations & 812 & 812 \\
\hline
\end{tabular}

(1) Dependent variable is log GDP per worker. (2) Figures in parentheses are standard errors. (3) *** represents $1 \%$ statistical significance

capital shown in the table may be an indication of problems with China's extensive growth - a strategy which relies heavily on investing aggressively. The human capital variable registers a positive coefficient and falls just below the $10 \%$ significance level based on CCEMG and is statistically no different from zero according to the AMG method.

Turning to the focus of the study, we find the estimated coefficient of infrastructure is positive and highly significant in statistical terms, irrespective of the econometric techniques used. The magnitude of the coefficient is 0.126 or 0.148 , in the range of estimates in cross-country studies which use samples including developing economies and employ indicators of individual infrastructural sectors. The coefficients are also similar in size to those found on electricity and telecoms infrastructure for a full sample of Chinese provinces in Zhang and Ji (2018) and that on transport stocks in Yu et al. (2012). The magnitude of infrastructure's coefficient in our analysis is relatively larger in comparison with the results of Calderón et al. (2015) in which a composite infrastructure indicator is registered with a coefficient around 0.8 for a sample of 88 industrial and developing countries including China. One plausible explanation is that our larger coefficient may reflect an overall underprovision of infrastructure at the national level in China, whilst the Calderón et al. (2015) study includes some sample countries in which there is an oversupply of infrastructure and/or factors that hamper the materialisation of infrastructure's contribution to economic growth. Note that infrastructure capital appears twice in the augmented production function of Eq. (1)—once on its own and once as part of total physical capital. It's more appropriate to interpret the coefficient of the infrastructure variable as the output effect of increasing infrastructure stocks when holding overall physical capital constant. As pointed out by Canning (1999), Calderón and Servén (2004), Candelon et al. (2013) and Calderón et al. (2015), which all adopt the same approach, a positive and significant coefficient of infrastructure indicates that infrastructure capital is more productive than overall capital in boosting aggregate outputs. All in all, the results lead us to conclude that infrastructure is a strong determinant of economic growth in Chinese provinces.

One merit of the two econometric techniques is that they take into consideration unobserved common factors, which in the case of this study are shocks to GDP correlated across provinces. The estimation results shown in the second column of Table 4 are thus less prone to noises caused by events like the 1997 Asian financial crises, the 
2008 global financial crises and macroeconomic policies or measures implemented nationwide in China. Moreover, the CCEMG estimators can take into account multifactor error structures and spatial error correlation that are very likely in our sample of Chinese provinces. Therefore, the coefficient estimates obtained from these techniques are consistent even when there is nuisance spatial dependence across provinces (i.e. a province's growth is affected by changes in other provinces to the extent that the latter deviate from their steady-state equilibrium). ${ }^{6}$

To explore the robustness of the results, we replicate the same exercise using the alternative measure of infrastructure-the composite indicator constructed from the standard PCA. Table 5 reports the results. The estimated coefficients of physical capital are very similar, in terms of size, to those shown in Table 4. So are the estimates of the output elasticity of human capital, although it becomes marginally significant based on the method of CCEMG. It seems that the parameter estimates of the alternative infrastructure indicator are slightly smaller than those of the robust-PCA index. A close look at the two synthetic indices reveals that the outliers fall into two types. One includes observations in the earlier years of the sample period on provinces like Jiangsu, Zhejiang and Shandong, which turned out to have not very low GDP but relatively poor infrastructure endowments at the time. This phenomenon occurred in the early years of China's economic reform when such provinces had to overstretch on their limited infrastructure facilities which had not been fed with much state investment. The other group of outliers are the data points covering the most recent years of the sample period for provinces like Qinghai, Inner Mongolia and Xinjiang, which have received heavy investment in infrastructure under the 'Open-up the West' program and as part of the country's plan to transform them into major energy suppliers. It seems that leaving the outliers undealt with tends to produce lower estimates for the effects of infrastructure, because for the former group it suggests that infrastructure is not much required to generate high output and for the latter it implies that high infrastructure stocks do not lead to more output. Nonetheless, the coefficient estimates are positive and statistically significant, confirming that infrastructure plays an important role in promoting growth in China.

We also conduct another robustness check by adopting the CupBC (continuously updated and bias corrected) and CupFM (continuously updated and fully modified) estimators proposed by Bai et al. (2009). The two estimators, which are iterative in nature, are able to accommodate cross-sectional dependence generated by unobserved global stochastic trends and allow for the joint estimation of the slope parameters and the stochastic trends. Another appealing aspect of the estimators is that they remain valid in the presence of mixed stationary and non-stationary factors, as well as the observed regressors. The estimation results are summarised in Table 6. Overall, they are qualitatively similar to those obtained from the CCEMG and AMG estimators.

The above analysis tells us that a long-run relationship exists among the variables in Eq. (1). To complement the analysis and investigate the direction of causality, we employ the procedure developed by Dumitrescu and Hurlin (2012), as discussed

\footnotetext{
6 There is contention in the literature that spatial dependence is of a substantive type (i.e. spatial spillovers arising from technological diffusion and pecuniary externalities) rather than a nuisance case caused by regional transmission of random shocks. Nonetheless, it is at large outside the scope of our paper.
} 
Table 5 Estimation of long-run elasticities of output: alternative infrastructure index (period = 1985-2012; no. of provinces $=29$ )

\begin{tabular}{lll}
\hline & $(1)$ & $(2)$ \\
& CCEMG & AMG \\
\hline Physical capital & $0.255^{* * *}(0.073)$ & $0.207^{* * *}(0.022)$ \\
Human capital & $0.296^{*}(0.180)$ & $0.0791(0.093)$ \\
Infrastructure 2 & $0.106^{* * *}(0.024)$ & $0.121^{* * *}(0.018)$ \\
Constant & $-0.149(0.142)$ & $0.626^{* * *}(0.099)$ \\
Observations & 812 & 812 \\
\hline
\end{tabular}

(1) Dependent variable is log GDP per worker. (2) Figures in parentheses are standard errors. (3) *** represents $1 \%$ statistical significance

Table 6 Estimation of long-run elasticities using estimators proposed in Bai et al. (2009)

\begin{tabular}{lrr}
\hline & \multicolumn{1}{c}{$(1)$} & \multicolumn{1}{l}{$(2)$} \\
& \multicolumn{1}{c}{ CupFM } & \multicolumn{1}{c}{ CupBC } \\
\hline Panel A & & \\
Physical capital & $0.285^{* * *}(0.019)$ & $0.289^{* * *}(0.009)$ \\
Human capital & $-0.013(0.038)$ & $-0.006(0.022)$ \\
Infrastructure_robust & $0.089^{* * *}(0.008)$ & $0.092^{* * *}(0.005)$ \\
\hline Panel B & & $0.335^{* * *}(0.011)$ \\
Physical capital & $0.307 * * *(0.019)$ & $0.034(0.020)$ \\
Human capital & $0.027(0.038)$ & $0.074 * * *(0.006)$ \\
Infrastructure 2 & $0.076^{* * *}(0.008)$ &
\end{tabular}

(1) Dependent variable is log GDP per worker. (2) Figures in parentheses are standard errors. (3) *** represents $1 \%$ statistical significance. (4) CupFM refers to the continuously updated and fully modified estimator and $\mathrm{CupBC}$ the continuously updated bias-corrected estimator

in Sect. 3.5. Table 7 presents the results, which indicate that causality runs from infrastructure to output. This finding remains robust irrespective of the measures of infrastructure used. Thus, it is fair to say that the estimates of infrastructure's coefficient obtained from our analysis have not mixed up the output elasticity of infrastructure with the income elasticity of the demand for infrastructure.

So far the analysis has assumed a common linear production function for all provinces. It is possible that there are regional differences in the impact of infrastructure in a country like China. To this end, we obtain the estimates for individual provinces and present the coefficient of the infrastructure variable obtained from the CCEMG and AMG techniques in the first two columns of Table 8. Provinces are grouped into three regions according to the classification which is based principally on geographical location but also reflects the differences in economic development, with the eastern region being the most developed and the western area the least developed. It is evident from the results that the estimated coefficient of infrastructure is positive and significant in all the coastal provinces, with a magnitude larger than that obtained from the full sample in the majority of the cases. It is in general smaller for 
Table 7 Heterogenous panel causality

\begin{tabular}{llr}
\hline Null hypothesis & Z-bar statistic & Prob. \\
\hline Index: infrastructure_robust & & 0.025 \\
Infrastructure does not cause GDP & $2.247^{* * *}$ & 0.134 \\
GDP does not cause infrastructure & 1.499 & 0.016 \\
\hline Index: infrastructure 2 & & 0.163 \\
Infrastructure does not cause GDP & $2.418^{* *}$ & 1.394 \\
GDP does not cause infrastructure & & \\
\hline
\end{tabular}

(1) ** Represents rejection of null hypothesis at the 5\% significance level. (2) The analysis is conducted using MATLAB, with the maximum lags set at 5

the provinces in the central region and even turns negative in the cases of Guangxi and Jiangxi (although insignificant). In the western region, the estimated parameter is statistically no different from zero for at least half of the provinces, indicating there is no discernible impact of infrastructure on economic growth or, more precisely, infrastructure stocks there are no more productive than overall physical capital.

The cross-province heterogeneity in infrastructure's effect may be due to various reasons. A possible explanation lies in quality differences in infrastructure across provinces. It is agreed in the literature that the effectiveness of infrastructure depends crucially on its quality. Despite a lack of comprehensive data on the quality of provincial infrastructure stocks, there have been observations that coastal areas are endowed with better quality infrastructure (e.g. more high-speed railways and better maintenance of highways) (Bai and Qian 2010; Yu et al. 2012). Differences in quality and maintenance of infrastructure may have contributed to differences in infrastructure's growth-enhancing role.

Another plausible explanation is the one we have used to explain the relatively higher output elasticity of infrastructure found in our analysis in comparison with that of the cross-country study of Calderón et al. (2015); that is, the relative shortage or oversupply of infrastructure capital. As indicated by Canning and Pedroni (2007), Aschauer (2000) and Cadot et al. (2006), the extent to which an increase in infrastructure (at the price of lowering investment in other physical capital) can raise aggregate outputs depends on an optimal allocation between the two types of capital. Following this line of argument, it is predicted that the efficacy of infrastructure varies according to the ratio of the two types of capital. To examine whether the relative shortage or oversupply of infrastructure is a possible explanation to the provincial differences in the coefficient estimate, we compute the ratio of infrastructure stocks (the robustPCA measure) to total physical capital. Due to the lack of data on costs or prices of constructing infrastructure facilities, we are unable to construct ratios with both types of capital measured in the monetary terms. Nonetheless, the ratios constructed in this paper are comparable across provinces and over time. The last column of Table 8 shows the ratios of individual provinces averaged over the sample period. It can be seen that, roughly speaking, high ratios are more likely to associate with low and/or insignificant coefficients of the infrastructure variable. 
Table 8 Estimation of long-run elasticity of output with regard to infrastructure: individual provinces

\begin{tabular}{|c|c|c|c|}
\hline & CCEMG & AMG & Infrastructure $/ k$ ratio \\
\hline Beijing & $0.417 * * *$ & $0.667 * * *$ & 192.786 \\
\hline Fujian & $0.386 * * *$ & $0.159 * *$ & 48.5352 \\
\hline Guangdong & $0.162 * * *$ & $0.146^{* *}$ & 167.566 \\
\hline Hainan & $0.176 * * *$ & $0.165^{* * *}$ & 108.485 \\
\hline Hebei & $0.109 *$ & 0.031 & 128.851 \\
\hline Jiangsu & $0.167 * * *$ & $0.220 * * *$ & 58.5927 \\
\hline Liaoning & $0.410 * * *$ & $0.263 * * *$ & 151.441 \\
\hline Shandong & $0.138 * *$ & $0.077 *$ & 76.8465 \\
\hline Shanghai & $0.165 * * *$ & $0.175 * * *$ & 14.6139 \\
\hline Tianjin & $0.199 * *$ & $0.252 * * *$ & 28.5300 \\
\hline Zhejiang & $0.176 * *$ & $0.130 * *$ & 104.924 \\
\hline Eastern region average & $0.228 \#$ & $0.204 \#$ & $98.288 \#$ \\
\hline Anhui & $0.130 * *$ & $0.075^{* *}$ & 192.786 \\
\hline Guangxi & -0.063 & -0.063 & 198.302 \\
\hline Heilongjiang & $0.282 * *$ & $0.350 * *$ & 160.622 \\
\hline Henan & $0.134 * *$ & $0.149 * *$ & 123.131 \\
\hline Hubei & $0.135 * * *$ & $0.059 * *$ & 179.637 \\
\hline Hunan & $0.059 * *$ & $0.058 * *$ & 200.803 \\
\hline Inner Mongolia & $0.058 *$ & $0.083 * * *$ & 285.085 \\
\hline Jiangxi & -0.148 & 0.039 & 240.119 \\
\hline Jilin & $0.246 * * *$ & $0.321 * * *$ & 157.559 \\
\hline Shanxi & $0.107 * * *$ & $0.067 * *$ & 138.846 \\
\hline Central region average & $0.115 \#$ & $0.120 \#$ & 187.689\# \\
\hline Gansu & -0.155 & -0.156 & 245.800 \\
\hline Guizhou & $0.083^{*}$ & 0.004 & 252.879 \\
\hline Ningxia & 0.130 & $0.161 *$ & 154.944 \\
\hline Qinghai & 0.028 & 0.020 & 410.142 \\
\hline Shaanxi & $0.106^{* *}$ & $0.150 * *$ & 154.287 \\
\hline Sichuan & $0.114 * * *$ & $0.118 * * *$ & 105.843 \\
\hline Xinjiang & 0.026 & $0.038^{*}$ & 243.165 \\
\hline Yunnan & -0.128 & 0.019 & 719.973 \\
\hline Western region average & $0.038 \#$ & $0.058 \#$ & $285.879 \#$ \\
\hline
\end{tabular}

(1) \# Regional averages of the coefficient are calculated based on province-specific coefficient estimates which are statistically significant. (2) ***, ** and * indicate statistical significance at 1,5 and $10 \%$ level, respectively

To shed further light on this, a panel threshold regression proposed by Hansen (1999) is carried out with the infrastructure-to-physical-capital ratio being the threshold variable. This is to see whether the effect of infrastructure varies according to the ratio, or whether there is nonlinearity in the effect conditional on the relative shortage or oversupply of infrastructure stocks. It should be noted that it is practically difficult 
(if not impossible) to integrate the CCEMG or AMG estimator into a panel threshold regression model. Therefore, we only undertake a standard threshold regression and the magnitude of the coefficients obtained are not directly comparable to those shown in Tables 4 and 5. The estimation reveals that there exists a single threshold and that infrastructure's coefficient is 0.041 and statistically significant when the ratio is smaller than 165 and it is -0.020 but statistically insignificant with higher ratios. The result implies that infrastructure complements other physical capital only to the extent that there is no relative oversupply. Although it is by no means a rigorous analysis, the exercise indicates that the marginal productivity of infrastructure tends to be higher in places with relative undersupply of infrastructure and low or even null in locations where infrastructure is too much in relation to other physical capital.

\section{Conclusions}

Infrastructure investment has long been used as a development tool, but its effectiveness remains a controversial issue among researchers and practitioners. One of the oldest debates in the literature is whether infrastructure capital contributes to aggregate output in the long run. A related question is whether it is beneficial to increase infrastructure investment in less developed regions to boost their growth. This paper attempts to shed empirical light on these issues by employing an infrastructure-augmented production function approach and drawing on the case of China, which has now become the world's largest investor in infrastructure. A panel data set of 29 Chinese provinces over the period 1985-2012 is analysed based on an econometric strategy which addresses some methodological limitations of earlier literature. Synthetic indices are constructed to capture multidimensionality of infrastructure, based on physical indicators of four types of infrastructure assets. The analysis deals explicitly with non-stationarity of the variables and tests for the direction of causality.

The analysis results show that infrastructure, on average, impacts positively on growth in China. Infrastructure capital is in general more productive than physical capital in boosting output. The causality test indicates that causality runs from infrastructure to growth. However, the analysis on individual provinces suggests that there are provincial differences in the impact of infrastructure, probably due to the differences in the relative overprovision or shortage of infrastructure. From the policy perspective, the findings provide empirical support for development strategies involving the use of infrastructure investment. It is desirable for countries or regions which suffer from inadequate infrastructure to increase infrastructure stocks and benefit in the long run. However, if the over- or under-supply explanation is plausible, the effectiveness of such policies may be limited if adopted by countries (developing and developed ones alike) or areas with high infrastructure stocks relative to, for instance, physical capital. In other words, policy makers should use infrastructure investment as a means of boosting growth or promoting regional development only to the extent that it does not lead to oversupply of infrastructure. 
Acknowledgements We are grateful to one anonymous referee and one of the editors for their comments which have helped us improve our paper.

Open Access This article is distributed under the terms of the Creative Commons Attribution 4.0 International License (http://creativecommons.org/licenses/by/4.0/), which permits unrestricted use, distribution, and reproduction in any medium, provided you give appropriate credit to the original author(s) and the source, provide a link to the Creative Commons license, and indicate if changes were made.

\section{Appendix}

See Tables 9 and 10.

Table 9 List of sample provinces and geographical regions

\begin{tabular}{lll}
\hline Eastern coastal area & & \\
Beijing & Hainan & Shanghai \\
Fujian & Hebei & Tianjin \\
Guangdong & Liaoning & Zhejiang \\
Jiangsu & Shandong & \\
Central area & & \\
Anhui & Inner Mongolia & Shanxi \\
Heilongjiang & Jiangxi & Guangxi \\
Henan & Jilin & Hubei \\
Hunan & & \\
Western area & & Xinjiang \\
Gansu & Qinghai & Yunnan \\
Guizhou & Shaanxi & \\
Ningxia & Sichuan (including Chongqing) & \\
\hline
\end{tabular}

Table 10 Cross-sectional dependence test for individual variables

\begin{tabular}{lrc}
\hline & CD-test & $p$ value \\
\hline Output & 99.74 & 0.00 \\
Physical capital & 104.43 & 0.00 \\
Human capital & 103.95 & 0.00 \\
Infrastructure robust & 101.77 & 0.00 \\
\hline
\end{tabular}

\section{References}

Agénor PR (2010) A theory of infrastructure-led growth. J Econ Dyn Control 34:932-950

Arrow KJ, Kurz M (1970) Public investment, the rate of return, and optimal fiscal policy. The Johns Hopkins University Press, Baltimore

Aschauer DA (1989) Is public expenditure productive? J Monet Econ 23:177-200

Aschauer DA (2000) Do states optimize? public capital and economic growth. Ann Reg Sci 34:343-363 
Bai C, Qian Y (2010) Infrastructure development in China: the cases of electricity, highways, and railways. J Comp Econ 38(1):34-51

Bai C, Hsieh C, Qian Y (2006) The return to capital in China. Brook Papers on Econ Act 2:61-88

Bai J, Kao C, Ng S (2009) Panel cointegration with global stochastic trends. J Econom 1:82-99

Barro RJ (1990) Government spending in a simple model of endogenous growth. J Polit Econ 98(5):103-126

Cadot O, Roller L, Stephan A (2006) Contribution to productivity or pork-barrel? the two faces of infrastructure investment. J Public Econ 90:1133-1153

Calderón C, Servén L (2004) The effects of infrastructure development on growth and income distribution. Working papers no. 270, Central Bank of Chile, Santiago

Calderón C, Moral-Benito E, Servén L (2015) Is infrastructure capital productive? A dymanic heterogeneous approach. J Appl Econom 30:177-198

Candelon B, Colletaz G, Hurlin C (2013) Network effects and infrastructure productivity in developing countries. Oxf Bull Econ Stat 75(6):887-913

Canning D (1999) Infrastructure's contribution to aggregate output. Policy research working paper series 2246, World Bank, Washington DC

Canning D, Bennathan E (2002) The social rate of return on infrastructure investments. Policy research working paper series 2390, World Bank, Washington DC

Canning D, Pedroni P (2007) Infrastructure, long-run economic growth and causality tests for cointegrated panels. Manch Sch 76(5):504-527

Demurger S (2001) Infrastructure development and economic growth: an explanation for regional disparities in China. J Comp Econ 29(1):95-117

Ding L, Haynes KE, Liu Y (2008) Telecommunications infrastructure and regional income convergence in China: panel data approaches. Ann Reg Sci 42:843-861

Dumitrescu EI, Hurlin C (2012) Testing for granger non-causality in heterogeneous panels. Econ Model 29(4):1450-1460

Eberhartd M (2012) Estimating panel time-series models with heterogeneous slopes. Stata J 12:61-71

Fan S, Chan-Kang C (2008) Regional road development, rural and urban poverty: evidence from China. Transp Policy 15:306-314

Ford R, Poret P (1991) Infrastructure and private-sector productivity. OECD Econ Stud 17:63-89

Gramlich EM (1994) Infrastructure investment: a review essay. J Econ Lit 32(3):1176-1196

Granger CWJ (1969) Investigating causal relations by econometric models and cross-spectral methods. Econom J Econom Soc 37(3):424-438

Hansen BE (1999) Threshold effects in non-dynamic panels: estimation, testing, and inference. J Econom 93:345-368

Hirschman AO (1957) Investment policies and "dualism" in underdeveloped countries. Am Econ Rev 47(5):550-570

Im KS, Pesaran MH, Shin Y (2003) Testing for unit roots in heterogeneous panels. J Econom 115:53-74

Johansen S (1992) Cointegration in partial systems and the efficiency of single-equation analysis. J Econom 52:389-402

Johansen S (1995) Likelihood-based inference in cointegration vector autoregressive models. Oxford Univerity Press, Oxford

Kao C (1999) Spurious regression and residual-based tests for cointegration in panel data. J Econom 90:1-44

Larsson R, Lyhagen J, Lothgren M (2001) Likelihood-based cointegration tests in heterogeneous panels. Econom J 4:109-142

Levin A, Lin CF, Chu CS (2002) Unit root tests in panel data: asymptotic and finite-sample properties. J Econom 108:1-24

Lucas RE (1988) On the mechanics of economic development. J Monet Econ 22:3-42

Munnell AH (1990) How does public infrastructure affect regional economic performance? N Engl Econ Rev 25:2-22

Munnell AH (1992) Policy watch: infrastructure investment and economic growth. J Econ Perspect 6:189-198

Naughton B (2007) The Chinese economy: transitions and growth. MIT Press, Cambridge

Pedroni P (2000) Fully modified OLS for heterogeneous cointegrated panels. In: Baltagi BH (ed) Nonstationary panels, panel cointegration, and dynamic panels. Elsevier, Amsterdam, pp 93-130

Pesaran MH (2006) Estimation and inference in large heterogenous panels with multifactor error structure. Econometrica 74:967-1012 
Pesaran MH (2007) A simple panel unit root test in the presence of cross-section dependence. J Appl Econom 22:265-312

Pesaran MH, Tosetti E (2011) Large panels with common factors and spatial correlations. J Econom 161:182-202

Romer PM (1986) Increasing returns and long run growth. J Polit Econ 94:1002-1037

Romer PM (1990) Endogenous technological change. J Polit Econ 98(5):71-102

Rosenstein-Rodan PN (1943) Problems of industrialisation of south-eastern Europe. Econ J 53(210/211):202-211

Shi H, Huang S (2014) How much infrastructure is too much? A new approach and evidence from China. World Dev 56(4):272-286

Shiu A, Lam PL (2008) Causal relationship between telecommunications and economic growth in China and its regions. Reg Stud 42(5):705-718

Yu N, De Jong M, Storm S, Mi J (2012) The growth impact of transport infrastructure investment: a regional analysis for China (1978-2008). Policy Soc 31:25-38

Yu N, De Jong M, Storm S, Mi J (2013) Transport infrastructure, spatial clusters and regional economic growth in China. Transp Rev Transnatl Transdiscipl J 32(1):3-28

Zhang Y, Ji S (2018) Does infrastructure have a transitory or longer-term impact? Evidence from China. Econ Model. https://doi.org/10.1016/j.econmod.2018.03.014

Zhang J, Wu G, Zhang J (2004) Estimation of physical capital stocks of Chinese provinces: 1952-2000. Econ Res 2004(10):35-44 (in Chinese) 